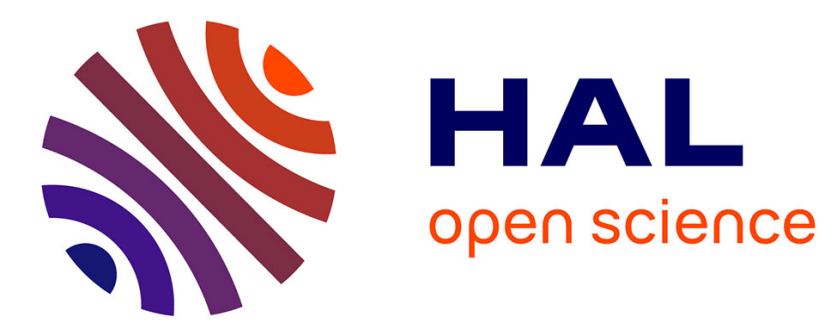

\title{
Photonic microwave oscillator based on monolithic DFB lasers with frequency-shifted feedback
} Lihua Wang, Marco Romanelli, Frederic van Dijk, Marc Vallet

\section{To cite this version:}

Lihua Wang, Marco Romanelli, Frederic van Dijk, Marc Vallet. Photonic microwave oscillator based on monolithic DFB lasers with frequency-shifted feedback. Electronics Letters, 2014, 50 (6), pp.451. 10.1049/el.2014.0155. hal-00967127v2

\section{HAL Id: hal-00967127 \\ https://hal.science/hal-00967127v2}

Submitted on 25 Aug 2014

HAL is a multi-disciplinary open access archive for the deposit and dissemination of scientific research documents, whether they are published or not. The documents may come from teaching and research institutions in France or abroad, or from public or private research centers.
L'archive ouverte pluridisciplinaire HAL, est destinée au dépôt et à la diffusion de documents scientifiques de niveau recherche, publiés ou non, émanant des établissements d'enseignement et de recherche français ou étrangers, des laboratoires publics ou privés. 


\section{Photonic microwave oscillator based on monolithic DFB lasers with frequency- shifted feedback}

\section{Wang, M. Romanelli, F. Van Dijk and M. Vallet}

A photonic oscillator, locked to a master RF synthesiser, was built by using a monolithic dual-wavelength DFB semiconductor laser submitted to a frequency-shifted optical feedback. A $[3 ; 10] \mathrm{GHz}$ tuning range is reported, with a phase noise level lower than $-70 \mathrm{dBrad}^{2} / \mathrm{Hz}$ at a $10 \mathrm{~Hz}$ offset from the carrier.

Introduction: The potentialities of optical heterodyning for photonic oscillators are now firmly established [1], the optically carried microwave being provided by the beat note between two laser modes. Active phase locking to a microwave local oscillator (LO), by means of analogue [2] or digital [3] phase-locked loops, has been shown to transfer the spectral purity of the LO to the beat note. However, such architectures inherently need a way to tune the frequency difference electronically. Conversely, optical injection locking schemes are free from electronics and it has been recently proved that dual-frequency erbium $\left(\mathrm{Er}^{3+}\right)$-doped lasers can be locked to an external LO by using an optical feedback frequency-shifted with a Bragg cell [4]. However, optical injection in rare earth lasers presents a small locking range. Since semiconductors are well known to be sensitive to injection with a large locking range [5], we choose here to use DFB lasers. Moreover, the use of a Bragg cell for a single-side-band modulation limits the frequency to below the gigahertz range [4]. We thus propose in this Letter to submit the DFB to an intensity modulated optical feedback by using an electro-optic modulator (EOM), in order to benefit from the bandwidth (BW) of EOMs.

Experimental setup: The optical source at $1.55 \mu \mathrm{m}$ is similar to the one described in [6]. It consists of two $2.5 \mathrm{~mm}$-long DFB semiconductor lasers grown on the same wafer (see the inset of Fig. 1). The lasers are electrically pumped by two current sources, so that both frequencies $v_{1}$ and $v_{2}$ can be tuned independently using the bias currents $I_{1}$ and $I_{2}$. The two output beams are coupled by a $-3 \mathrm{~dB}$ coupler providing a $7^{\circ}$ angled output to reduce back reflections, followed by a lens fibre and a 20/80 coupler. The $26 \mathrm{~m}$-long feedback loop contains a Mach-Zehnder intensity modulator $(\mathrm{EOM}, \mathrm{BW}=10 \mathrm{GHz})$ driven by a synthesiser which provides a frequency reference $f_{\mathrm{LO}}$. Next, an erbium-doped fibre amplifier (EDFA, $30 \mathrm{~dB}$ gain) and a programmable attenuator (from 0 to $-60 \mathrm{~dB}$ ) allow controlling the feedback power. An optical circulator closes the loop. The power sent back to the DFBs is monitored from one output of the coupler. The other output provides the useful output beam, whose beat note is analysed by an InGaAs photodiode (40 GHz BW) followed by an electrical spectrum analyser.

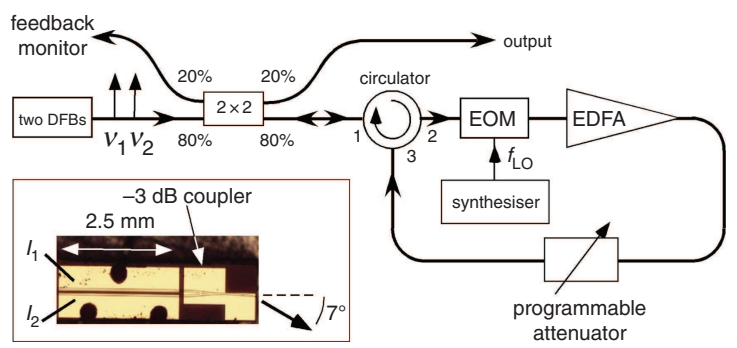

Fig. 1 Schematic of setup (see text for details)

Results: The typical power coupled into the fibre is $1 \mathrm{~mW}$. In the free running regime, the frequency difference $\Delta v=v_{1}-v_{2}$ is finely tunable from 0.3 up to $15 \mathrm{GHz}$ by sweeping the bias current of one DFB section from 230 to $440 \mathrm{~mA}$, whereas the other is biased at a constant current of $200 \mathrm{~mA}$. It is important to note that $\Delta v$ is much more stable than $v_{1}$ and $v_{2}$, since the two lasers share the same temperature fluctuations on the chip. The $-3 \mathrm{~dB}$ linewidth of the beat note is $630 \mathrm{kHz}$ for typical bias currents that are, respectively, 320 and $194 \mathrm{~mA}$, as shown in Fig. $2 a$.
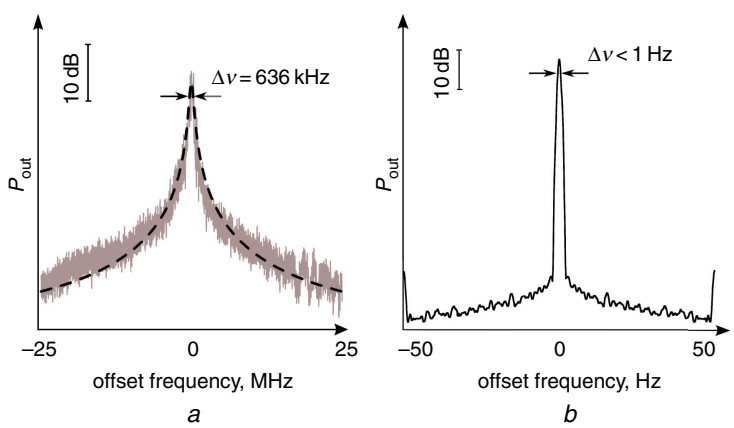

Fig. 2 Beat note RF spectra

Solid line: measured data; dashed line: Lorentzian fit a Free running, RBW: $30 \mathrm{kHz}$, span: $50 \mathrm{MHz}$

$b$ With feedback, RBW: $1 \mathrm{~Hz}$, span: $100 \mathrm{~Hz}$

When the optical feedback loop is closed, if the reinjected light is sufficient, the beat note locks to $f_{\mathrm{LO}}$. In this case, the $-3 \mathrm{~dB}$ linewidth of the beat note is measured to be equal to $1 \mathrm{~Hz}$, with the instrument limited (see Fig. 2b). Furthermore, the laser remains stable and locked for several hours. The beat note can be locked from 3 to $10 \mathrm{GHz}$. The lower boundary is set by the relaxation oscillation frequency that are known to destabilise injection locking [5], and the upper one is fixed by the BW of the electronic amplifier for the EOM. In the experiments described below, we chose the frequency of the beat note at $7.3 \mathrm{GHz}$.

Fig. 3 reports the locking range against the feedback level $\eta$. The latter is defined as the ratio of the amplitude of the feedback optical field with respect to the laser output optical field. We observe that when the feedback level goes from 0.02 to 1.2 , the locking range increases linearly, as in the master-slave injection locking. Moreover, a locking range as large as $1 \mathrm{GHz}$ can be demonstrated. For low feedback levels, the locking range is typically of several tens of megahertz. The modulation depth of the EOM was independently measured to be equal to $80 \%$. At variance with experiments using pure frequency-shifters [4], a certain amount of self-injection is unavoidable in our setup. Namely, not only the frequencies $v_{1} \pm f_{\mathrm{LO}}, v_{2} \pm f_{\mathrm{LO}}$, but also $v_{1}$ and $v_{2}$ are reinjected. Yet, our experiment shows that, at least in the explored range of parameters, self-injection does not seem to play an important role.

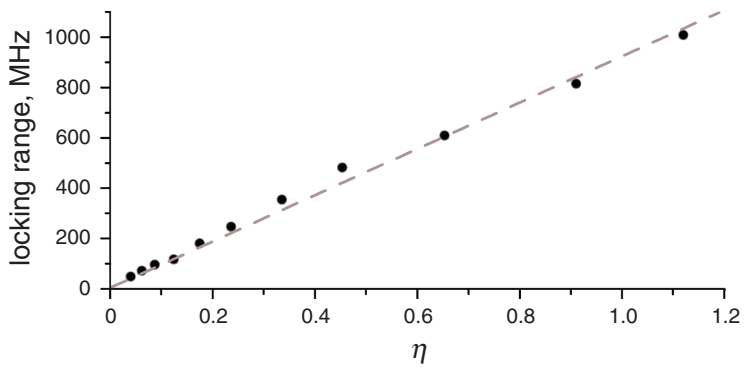

Fig. 3 Measured locking range with different feedback levels Dots: measured data; dashed line: linear fit

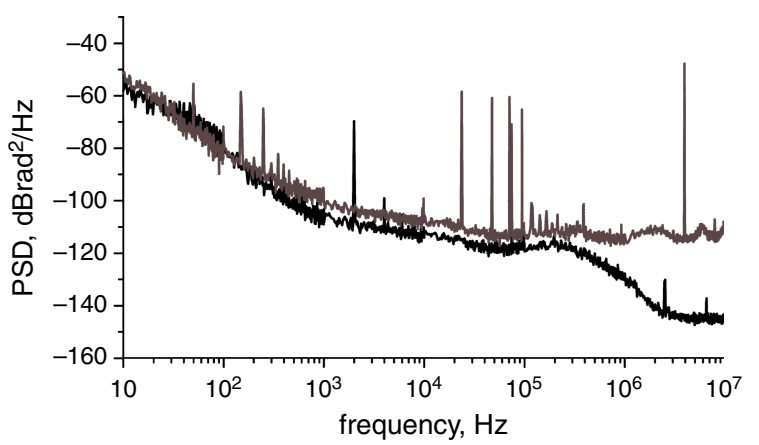

Fig. 4 Measured phase noise spectra

Grey: photonic RF oscillator; black: noise floor

To characterise the spectral purity of the photonic oscillator, we have measured the phase noise spectrum in the locking regime. As shown in 
Fig. 4, it coincides with the noise floor of the detection at low frequency, showing that our oscillator has a better stability than the available measurement apparatus. The phase noise is thus lower than $-70 \mathrm{dBc} / \mathrm{Hz}$ at $10 \mathrm{~Hz}$ from the carrier. To check the insensitivity of the locking to the length of the loop, we inserted a delay line $(700 \mathrm{~m}$, $\tau=3.5 \mu \mathrm{s})$ in the feedback loop. We could hardly measure a difference between these two cases.

Conclusion: We have demonstrated a photonic oscillator based on monolithic DFB semiconductor lasers, driven by a master microwave synthesiser. The oscillator is stable, finely tunable and displays a large locking range and a low phase noise level. Our scheme could be extended to the millimetre-wave frequencies [7] by using, for example, an inloop fast EOM or harmonics from a nonlinear modulator [8].

Acknowledgments: We thank L. Frein, S. Bouhier and G. Loas for technical assistance and M. Alouini and M. Brunel for fruitful discussion. Partial funding from the French Defence Agency (project Astrid Minotor) is acknowledged.

(C) The Institution of Engineering and Technology 2014

13 January 2014

doi: $10.1049 / \mathrm{el} .2014 .0155$

One or more of the Figures in this Letter are available in colour online.

L. Wang, M. Romanelli and M. Vallet (Institut de Physique de Rennes, UMR Université de Rennes 1 - CNRS 6251, Campus de Beaulieu, 35042 Rennes Cedex, France)

E-mail: marc.vallet@univ-rennes1.fr
F. Van Dijk (III-V Laboratory, a Joint Lab of Thales Research and Technology, Alcatel-Lucent Bell Labs France and CEA Leti, 91767 Palaiseau Cedex, France)

\section{References}

1 Lee, C.H.: 'Microwave photonics' (CRC - Taylor and Francis, Boca Raton, FL, 2013, 2nd edn)

2 Gliese, U., et al.: 'A wideband heterodyne optical phase-locked loop for generation of 3-18 GHz microwave carriers', IEEE Photonics Technol. Lett., 1992, 4, (8), pp. 936-938

3 Rolland, A., Frein, L., Vallet, M., Brunel, M., Bondu, F., and Merlet, T. ' $40 \mathrm{GHz}$ photonic synthesizer using a dual-polarization microlaser', IEEE Photonics Technol. Lett., 2010, 22, pp. 1738-1740

4 Kervevan, L., Gilles, H., Girard, S., and Laroche, M.: 'Beat-note jitter suppression in a dual-frequency laser using optical feedback', Opt. Lett., 2007, 32, (9), pp. 1099-1101

5 Wieczorek, S., Krauskopf, B., Simpson, T.B., and Lenstra, D.: 'The dynamical complexity of optically injected semiconductor lasers', Phys. Rep., 2005, pp. 1-128

6 Van Dijk, F., Accard, A., Enard, A., Drisse, O., Make, D., and Lelarge, F.: 'Monolithic dual wavelength DFB lasers for narrow line width heterodyne beat-note generation'. Proc. 2011 IEEE Int. Topical Meeting on Microwave Photonics, Singapore, October 2011, p. 73

7 Carpintero, G., et al.: '95 GHz millimeter wave signal generation using an arrayed waveguide grating dual wavelength semiconductor laser', Opt. Lett., 2012, 37, pp. 3657-3659

8 Rolland, A., Loas, G., Brunel, M., Frein, L., Vallet, M., and Alouini, M. 'Non-linear optoelectronic phase-locked loop for stabilization of optomillimeter waves: towards a narrow linewidth tunable $\mathrm{THz}$ source', Opt. Express, 2011, 19, pp. 17944-17950 